\title{
Squamous cell carcinoma in situ of the endometrium - A case report with review of the literature
} \author{
Tawfik $^{1,3, *}$, MD, PhD \\ ${ }^{1}$ Department of Pathology, St. Luke's Hospital System of Kansas City, Kansas City, Missouri, USA \\ 2 Department of Gynecology, St. Luke's Hospital System of Kansas City, Kansas City, Missouri, USA \\ ${ }^{3}$ MAWD Pathology Group, Saint Luke's Health System, 4401 Wornall Road, Kansas City, MO 64111, USA
}

Christopher Ward ${ }^{1}$, MD, Richard FC Hill ${ }^{2}$, MD, Pradip Mana ${ }^{3}$, PhD, Russell Smith ${ }^{3}$, MT(ASCP), Bradley Carmichael ${ }^{1,3}$, MD and Ossama

\begin{abstract}
This is a rare case report of an extensive squamous cell carcinoma in situ of the endometrium (ESCC-I) in a 79-year-old nulliparous female that was diagnosed incidentally following hysterectomy due to her prolapsed uterus. The progression of ESCC-I was consistent with the cephalic spread from a cervical high-grade intraepithelial lesion/squamous cell carcinoma in situ. Both lesions were confirmed to have developed through a human papillomavirus (HPV) driven mechanism (p16, p40, HPV-16 positive). The clinical, histopathological and molecular studies are discussed along with review of the literature.
\end{abstract}

Keywords: HPV; human papilloma virus; endometrial squamous cell carcinoma; endometrial cancer

\section{Introduction}

Primary endometrial squamous cell carcinoma (ESCC) is a rare histologic type of endometrial cancer representing less than $0.5 \%$ of endometrial carcinomas [1]. Endometrial squamous cell carcinoma in situ (ESCC-I) is even a more uncommon finding with very few reported cases in the world literature [2-7].

We presented a case of incidental extensive involvement of the endometrium by ESCC-I and patchy, asymptomatic, high-grade squamous intraepithelial lesion (HSIL)/ squamous cell carcinoma in situ in the endocervix of a prolapsed uterus of a 79-year-old patient. This case is an example of where screening guidelines are lacking in modifiers to specific risk factors for cervical cancer screening, in addition to supporting the necessity of identifying and standardizing an appropriate endometrial cancer screening method.

\section{Case report}

The patient in a 79-year-old nulliparous Caucasian female who presented to the urogynecological specialist with a one-year history of pelvic pain, urinary incontinence, and urinary urgency. The patient's past medical history was significant for a partial vaginal enterocele, a partial rectocele, paravaginal defect, and an incomplete uterine prolapse. Menopause was reached at age 51. The patient is a widow, who denied any recent sexual activity, as well as emotional, physical, or sexual abuse. Family history was noncontributory. She denied any smoking history but endorsed drinking socially and endorsed living a solitary lifestyle.

The patient received annual pap smears for 18 years until the age of 70 that were only remarkable for atypical squamous cells of undetermined significance (ASCUS), 19 and 20 years prior to presentation. Colposcopy and cervical biopsy at the time showed what was reported as "focal superficial koilocytosis". There was no records of high risk HPV testing in the available medical records for the patient. Screening pap smears were discontinued at 70 years of age in agreement with US Preventive Task Force recommendations, in the setting of a history of ASCUS,

\footnotetext{
*Corresponding author: Ossama Tawfik, MD, PhD., Department of Pathology, Saint Luke's Health System of Kansas City, MAWD Pathology Group, 4401 Wornall Road, Kansas City, MO 64111, USA. Tel: 816-932-2447; Email: otawfik@mawdpathology.com

Received 25 September 2019 Accepted 22 October 2019 Published 1 November 2019

Citation: Ward C, Hill RFC, Mana P, Smith R, Carmichael B, Tawfik O. Squamous cell carcinoma in situ of the endometrium - A case report with review of the literature. J Mod Hum Pathol. 2019; 4(2):6-9. DOI: 10.14312/2397-6845.2019-2

Copyright: (c) 2019 Ward C, et al. Published by NobleResearch Publishers. This is an open-access article distributed under the terms of the Creative Commons Attribution License, which permits unrestricted use, distribution and reproduction in any medium, provided the original author and source are credited.
} 
until a recent episode of menorrhagia in three years prior to presentation. These symptoms required an endometrial biopsy and pap testing. Biopsy findings were reported to be unremarkable and the pap test was reported as ASCUS at the time.

Physical examination on admission was remarkable for a $3^{\text {rd }}$ degree rectoenterocele, a $2^{\text {nd }}$ degree anterior vaginal wall prolapse, a $2^{\text {nd }}$ degree uterine wall prolapse. No imaging was performed, or indicated, prior to surgical intervention. She was diagnosed with a complete uterine prolapse and elected to undergo a total vaginal hysterectomy with bilateral salpingo-oophorectomy. Surgery also involved a paravaginal defect repair, a posterior colporrhaphy, and a vaginal wall suspension. Intraoperatively, severe adhesions surrounding the left ureter were identified.

The surgical specimen consisted of the uterus with attached cervix, fallopian tubes, and ovaries. The uterus measured $7.2 \times 5.0 \times 2.6 \mathrm{~cm}$ and weighed 64 grams. The cervical os was noted to be stenosed measuring less than $0.1 \mathrm{~cm}$ in diameter. The uterus was bisected coronally to reveal two small endocervical polyps. No other masses or lesions were noted within the cervical tissue grossly. The endometrium revealed a small $1.0 \times 0.4 \times 0.4 \mathrm{~cm}$ endometrial polyp on the anterior wall. The endometrium was otherwise grossly unremarkable, measuring $0.1 \mathrm{~cm}$ in thickness. A calcified $0.5 \mathrm{~cm}$ subserosal leiomyoma was noted posteriorly. The left fallopian tube was found to have a $1 \mathrm{~cm}$ hydatid cyst. Bilateral ovaries had multiple serous inclusion cysts; all of them less than or equal to $0.7 \mathrm{~cm}$ in diameter.

On microscopic examination, multiple foci of HSIL/ squamous cell carcinoma in situ were noted to involve the endometrium including the endometrial polyp (Figures 1a, b and c) and endocervical tissue (Figure 1d). Sampling of the entire cervical tissue and extensive sampling of the endometrial tissue showed no evidence of invasion. A panel of immunohistochemical stains was performed, revealing strong positivity for $\mathrm{p} 40$ and $\mathrm{p} 16$ confirming the squamous nature of the lesions (Figures $2 a$ and $2 b$, respectively). Additional confirmatory molecular tests detected high risk HPV-16 in both cervical and endometrial tissue, as well as a positive Roche HPV test, detecting other high risk HPVtypes including 31,33,39,45,51,52,56,58,59,66, and/or 68 grouped together in the endocervical lesion.

The patient's postoperative course was remarkable electrolyte disturbances, hypokalemia and hypochloremia, on the postoperative day 2 . This resulted in an upgrade to ICU status. The patient was evaluated for pulmonary embolism as a postoperative concern and was found negative by chest X-ray and computed tomography (CT) angiography. A CT abdomen was performed in order to rule out other postoperative complications and was unremarkable. Concern for a persistent leukocytosis was addressed by a consult to infectious disease and was confirmed to be post-surgical leukocytosis. Blood and incision site cultures were negative. The patient was discharged home a week later without complications.
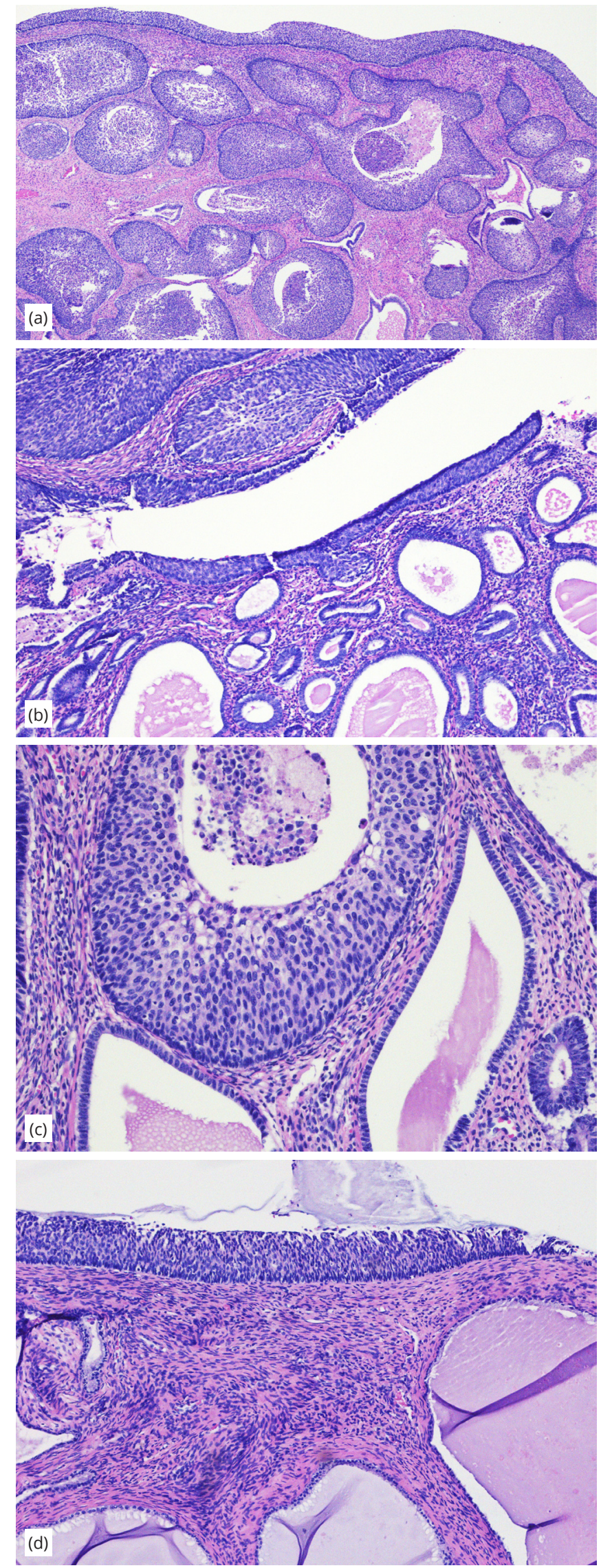

Figure 1 Composite photomicrography showing squamous cell carcinoma in situ involving the endometrium: (a) Showing the endometrial polyp extensively involved by ESCC-I, while figures $1 \mathrm{~b}$ through $\mathrm{d}$ show focal involved by SCC-I in the endometrium and endocervix ( $a, b$ and $c)$ and endocervix (d) (Hematoxylin and eosin, magnification 40x, a \& b, 200x c and $100 \times \mathrm{d}$ ) 

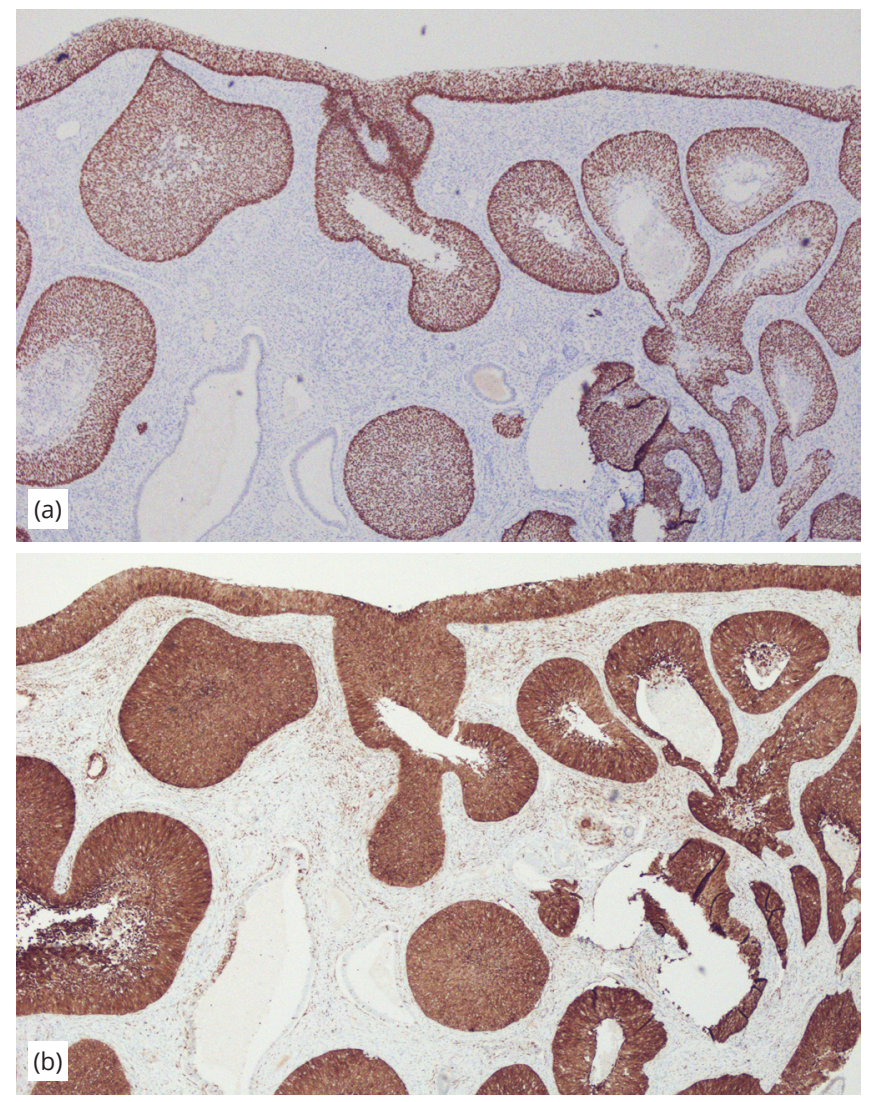

Figure 2 Photomicrograph of immunohistochemical stains of high-grade squamous intraepithelial lesion/squamous cell carcinoma in situ of the endometrium. p40 (Figure a) and p16 (b), (magnification 40x).

\section{Discussion}

Involvement of the endometrium by extensive ESCC-I is a rare condition. Usually these lesions are associated with intraepithelial or invasive SCC of the cervix. About $25 \%$ of low grade endometrial SCC are found incidentally at the time of hysterectomy [1]. The exact pathogenesis of ESCC is not known. Some investigators have suggested it originates from reserve or stem cells, others support squamous metaplasia of the endometrial glands and others believe heterotopic cervical tissue implicated [8]. HPV's role in the pathogenesis of ESCC is still under investigation. Some believe pure ESCC is unrelated to HPV and is p16 negative. Although HPV does not have a statistically significant association with ESCC, it is worth noting that HPV is detected in about $10 \%$ of all endometrial cancers [9]. Allegorically HPV-16 and HPV-31 have been reported in a small proportion of ESCCS. Those are believed to represent a superficial spreading from a known cervical SCC. However, due to the scarcity of this disorder that has an incidence of less than 1 in 100,000 women per year and accounting for about less than $0.5 \%$ of all uterine body cancers [10]. It is rather difficult to fully explain the relationship between the virus and ESCC. Oftentimes multiple molecular tests will detect it in the cervical epithelium, but will be negative in the endometrium [11].

In cases with ESCC and ESCC-I one has to follow the strict criteria proposed by Fluhmann including: (a) no evidence of a coexisting endometrial adenocarcinoma or primary cervical SCC, (b) no connection between endometrial tumor and squamous epithelium of the cervix, (c) no connection between any existing CIS and the independent endometrial lesions $[12,13]$. The ESCC-I presented in this report did not classically conform with the above criteria. Although there was evidence of CIS in the endocervix, there was no connection between the different endocervical and endometrial lesions. One must also consider "Icthyosis Uteri", defined as extensive squamous metaplasia of the endometrium, as a possibility in the pathogenesis of ESCC-I. However, upon microscopic examination there was no evidence of squamous metaplasia in the extensively sampled endometrial tissue. Two other verifiable cases of ESCC-I associated with ichthyosis uteri has been reported in the world literature. However, neither was p16 positive, excluding a viral origin for such tumors. The p16 positivity in our patient, supported that the tumor was driven by HPV related processes. In addition, HPV molecular tests confirmed the presence of HPV-16 in endometrial and cervical lesions.

Prior to the widespread vaccination against HPV, at least $40.5 \%$ of the population was positive for at least one typable strain [14]. This common oncogenic virus is associated, if not responsible, for more than $90 \%$ of cervical cancers at large [15]. It accounts for $99.7 \%$ of cervical carcinomas [16], and nearly $100 \%$ of cervical small cell carcinomas [17]. Risk factors for endometrial SCC in situ in general likely include HPV-31 and HPV-16 [3, 4, 8, 10]. Since repeat pap testing, with or without HPV testing, is recommended yearly with the finding of ASCUS or positive HPV tests. Alternatively, pap tests may be done every three years if cytology and HPV tests were negative for 3 years in a row or 2 years with HPV co-testing. This has been the American Society for Colposcopy and Cervical Pathology's consensus and management guideline for women age 30 years or older since 2012. Guidelines were applied to this patient, as well as considerations regarding women with a history of ASCUS, to the letter. Our patient was screened routinely and was regularly performing yearly pap testing since 1992 until 1999 where the initial diagnosis of ASCUS was given. A colposcopy was performed at the time and it was reported as negative for intraepithelial lesions or malignancy. Pap tests were stopped at age 70 and not repeated until 2016 when it was diagnostically indicated for endometrial bleeding. At that time a pap tested showed ASCUS and an endometrial biopsy was reported as negative for any abnormalities.

Our patient's condition challenges these guidelines and raises the concern of the need for continued screening in patients for a longer period in certain circumstances. Extending pap screening arguably should be correlated with the level of sexual activities for women 65 years or older. Multiple sexual partners and risk factors for sexual abuse should be considered. More data is needed for this to be addressed in a high risk pool with respect to screening guidelines. For now, testing should be done on a case by case basis.

While in vitro HPV antigen test in this disease is not infrequently negative $[10,18]$, PCR for HPV-16 seems to be consistently implicated. p16 positivity was found in this patient's lesion. If HPV is associated with the disease, then high risk sexual behavior is likely associated as well. Since 
most HPV strains are either resolved shortly after infection or precipitate into chronic infection, historical high risk sexual behavior may play a role in risk for the disease at presentation in the absence of prior or insufficient screening history. The risk ratio for contracting high risk $\mathrm{HPV}$ is about 2.8 times higher in high risk sexual behavior than in the general population [19]. Therefore, all the associated risk factors for high risk sexual behavior could play a role in risk. With $40-50 \%$ of geriatric adult females still endorsing sexually activity [20], this is not a risk factor that should go unaddressed. Factors associated with high risk sexual behavior include: prior separation/ divorce, prior or active smoking, and bisexuality, prior chronic disease, or frequent alcohol use [21]. Risk factors such as these should raise index of suspicion for necessity in screening.

It also should be noted that unexplained pap results and/ or HPV positivity also should trigger investigation into risk factors for and likelihood of sexual abuse. About $0.9 \%$ of the geriatric population endorsed being sexually abused within the last year and is in significantly associated with binge drinking [22]. Screening tools like an EASI, H-S/EAST, and VASS could serve some purpose. These likely should be present in any primary care setting and routinely administered regardless of screening guidelines.

\section{Conclusion}

This rare ESCC-I report is a unique manifestation of a very common problem. More research would have to be performed to validate the plausible mechanism of this disease. It is likely that a social modifier for screening guidelines should be applied to women over the age of 65 to account for lifestyle and environmental risks. Also, it was unlikely that a pap smear alone would detect endometrial cancer without significant endocervical involvement. New methods need to be developed to safely and efficiently screen for endometrial cancer. This unique disease, and related diagnoses, often go undiagnosed for greater than 11 months after the onset of symptoms [1]. This is a problem that will have to be addressed to improve outcomes.

\section{Funding and disclosures}

The authors of this work have no conflicts of interest to disclose. This project was funded privately by the principle investigator. Additional diagnostic tests for academic exercises courtesy of MAWD Pathology Group.

\section{References}

[1] Goodman A, Zukerberg LR, Rice LW, Fuller AF, Young RH, et al. Squamous cell carcinoma of the endometrium: a report of eight cases and a review of the literature. Gynecol Oncol. 1996; 61(1):54-60.

[2] Jain M, Kashyap A, Biswas R. Primary Endometrial Squamous Cell Carcinoma in-situ with Extensive Icthyosis Uteri: A Rare Case Report. J Clin Diagn Res. 2017; 11(8):ED13-ED14.

[3] Jetley S, Jairajpuri ZS, Hassan MJ, Madaan G, Jain R. Primary Endometrial Squamous Cell Carcinoma In Situ: Report of a rare disease. Sultan Qaboos Univ Med J. 2015; 15(4):e559-562.

[4] Kanbour Al, Stock RJ. Squamous cell carcinoma in situ of the endometrium and fallopian tube as superficial extension of invasive cervical carcinoma. Cancer. 1978; 42(2):570-580.

[5] Pins MR, Young RH, Crum CP, Leach IH, Scully RE. Cervical squamous cell carcinoma in situ with intraepithelial extension to the upper genital tract and invasion of tubes and ovaries: report of a case with human papilloma virus analysis. Int J Gynecol Pathol. 1997; 16(3):272-278.

[6] Razquin S, Mayayo E, Anton E, Alvira R. Squamous cell carcinoma in situ of the endometrium as superficial extension of cervical carcinoma. Gynecol Obstet Invest. 1993; 35(3):190-192.

[7] Radhika S, Dey P, Gupta S. Primary squamous cell carcinoma-in-situ of the endometrium--a case report. Indian journal of cancer. 1993; 30(2):92-95.

[8] Zhang C, Zhang H, Yang L, Wang Y, Li X, et al. Primary squamous cell carcinoma of the endometrium in a woman of perimenopausal age: $\mathrm{A}$ case report. Medicine (Baltimore). 2018; 97(48):e13418.

[9] Olesen TB, Svahn MF, Faber MT, Duun-Henriksen AK, Junge J, et al. Prevalence of Human Papillomavirus in endometrial cancer: a systematic review and meta-analysis. Gynecol Oncol. 2014; 134(1):206215.

[10] Farhane FZ, Alami Z, Bouhafa T, Elmazghi A, Hassouni K. Primary squamous cell carcinoma of endometrium: case report and literature review. Pan Afr Med J. 2018; 30:8. eCollection 2018.

[11] Lee SJ, Choi HJ. Primary endometrial squamous cell carcinoma: a case report and review of relevant literature on korean women. Korean J Pathol. 2012; 46(4):395-398.

[12] Kay S. Squamous-cell carcinoma of the endometrium. American journal of clinical pathology. 1974; 61(2):264-269.

[13] Jeffers MD, McDonald GSA, McGuiness EP. Primary squamous cell carcinoma of the endometrium. Histopathology. 1991; 19(2):177-179.

[14] Liu G, Markowitz LE, Hariri S, Panicker G, Unger ER. Seroprevalence of 9 Human Papillomavirus Types in the United States, 2005-2006. J Infect Dis. 2016; 213(2):191-198.

[15] Munoz N, Bosch FX, de Sanjose S, Herrero R, Castellsagué X, et al. Epidemiologic classification of human papillomavirus types associated with cervical cancer. N Engl J Med. 2003; 348(6):518-527.

[16] Walboomers JMM, Jacobs MV, Manos MM, Bosch FX, Kummer JA, et al. Human papillomavirus is a necessary cause of invasive cervical cancer worldwide. J Pathol. 1999; 189(1):12-19.

[17] Wang HL, Lu DW. Detection of human papillomavirus DNA and expression of $\mathrm{p} 16, \mathrm{Rb}$, and $\mathrm{p} 53$ proteins in small cell carcinomas of the uterine cervix. Am J Surg Pathol. 2004; 28(7):901-908.

[18] Wu Q, Chu Z, Han H, Bai S, Wu W, et al. Primary squamous cell carcinoma of the endometrium in a woman of reproductive age: a rare case report. J Int Med Res. 2018; 46(8):3417-3421.

[19] Winer RL, Hughes JP, Feng Q, Stern JE, Xi LF, et al. Incident Detection of High-Risk Human Papillomavirus Infections in a Cohort of High-Risk Women Aged 25-65 Years. J Infect Dis. 2016; 214(5):665-675.

[20] Thomas HN, Hess R, Thurston RC. Correlates of Sexual Activity and Satisfaction in Midlife and Older Women. Ann Fam Med. 2015; 13(4):336-342.

[21] Jackson SE, Yang L, Veronese N, Koyanagi A, López Sánchez GF, et al. Sociodemographic and behavioural correlates of lifetime number of sexual partners: findings from the English Longitudinal Study of Ageing. BMJ Sex Reprod Health. 2019; 45:138-146.

[22] Cannell MB, Manini T, Spence-Almaguer E, Maldonado-Molina M, Andresen EM. U.S. population estimates and correlates of sexual abuse of community-dwelling older adults. J Elder Abuse Negl. 2014; 26(4):398-413. 